\title{
Short-term effects of simultaneous using of two physiotherapeutic methods in the treatment of adolescent idiopathic scoliosis - continuation of study?
}

\author{
Bartosz Wnuk, Jacek Durmala*, Joanna Dzierzega, Katarzyna Dybula, Karol Wadolowski \\ From 7th International Conference on Conservative Management of Spinal Deformities \\ Montreal, Canada. 20-22 May 2010
}

\section{Aim of the study}

The assessment of influence short-term, intensive, joint physiotherapy (DoboMed and OMT KaltenbornEvjenth) to the function of the respiratory system and morphology of the trunk in the group of in-patient with Adolescent Idiopathic Scoliosis (AIS).

\section{Material and methods}

Forty girls with AIS (range of Cobb angle 15-35 degree) were examined. The group was divided into two randomized subgroups "D" $(\mathrm{N}=18)$ and "DK" $(\mathrm{N}=22)$. DoboMed was applied in group "D" (only). DoboMed and manual therapy was applied in the group "DK". Derotational stretch mobilization techniques in selected segments of thoracic spine were used as preparation for DoboMed's exercises. Physiotherapy has been continued for 3 weeks. The spirometry, maximal inspiration and expiratory pressures (MIP, MEP), kyphosis and the angle of trunk rotation (ATR-Bunnell) in thoracic spine have been estimated before and after therapy.

\section{Results}

MIP and MEP were increased significantly in both groups. Significantly changes were observed in the group "DK" as: increasing of forced expiratory volume in one second (FEV1), increasing of thoracic kyphosis and decreasing of ATR-Bunnell.

Department of Rehabilitation,Medical University of Silesia, Katowice, Poland Full list of author information is available at the end of the article

\section{Conclusions}

1.Physiotherapeutic methods provides to the functionally improvement of respiratory system in the group of in-patient with AIS in the short time.

2.Using of joint physiotherapeutic methods (DoboMed and OMT Kaltenborn-Evjenth) provides to the functionally improvement of respiratory system and to changes morphology of the trunk in the short time.

3.OMT Kaltenborn-Evjenth's derotational manual stretch mobilization techniques are useful to prepare patients for DoboMed's exercises.

Published: 10 September 2010

doi:10.1186/1748-7161-5-S1-O27

Cite this article as: Wnuk et al:: Short-term effects of simultaneous using of two physiotherapeutic methods in the treatment of adolescent idiopathic scoliosis - continuation of study? Scoliosis 2010 5(Suppl 1):O27.

Submit your next manuscript to BioMed Central and take full advantage of:

- Convenient online submission

- Thorough peer review

- No space constraints or color figure charges

- Immediate publication on acceptance

- Inclusion in PubMed, CAS, Scopus and Google Scholar

- Research which is freely available for redistribution 